\title{
Phylogenetic Relationship of Cowdria ruminantium, Agent of Heartwater, to Anaplasma marginale and Other Members of the Order Rickettsiales Determined on the Basis of 16S rRNA Sequence $\dagger$
}

\author{
JOHN B. DAME,* SUMAN M. MAHAN, AND CHARLES A. YOWELL \\ Department of Infectious Diseases, University of Florida, Gainesville, Florida 32611-0633
}

\begin{abstract}
The phylogenetic relationship between Cowdria ruminantium and representative members of the orders Rickettsiales and Chlamydiales has been examined on the basis of the sequence of the 16S rRNA. Phylogeny reconstruction by using both parsimony and distance methods supports the conclusion that $C$. ruminantium is closely related to the Rickettsiales and in particular to the family Anaplasmataceae. A signature of nine base substitutions delineated the linkage of Anaplasma marginale with $C$. ruminantium and differentiated these two species from the 45 other members of the alpha group of Proteobacteria examined, and five of these base substitutions were unique among all members of the class Proteobacteria examined to date.
\end{abstract}

Heartwater, or cowdriosis, is a tick-borne disease of domestic and wild ruminants caused by the intracellular, rickettsialike pathogen, Cowdria ruminantium Cowdry 1925 (15). The disease is important in tropical Africa, where it is a major barrier to improved livestock production (13), and its presence on islands in the Caribbean Sea makes it a threat to livestock on the American mainland (1). C. ruminantium is the only species defined in the genus Cowdria Moshkovski 1947, and is currently placed in the order Rickettsiales, family Rickettsiaceae, tribe Ehrlichieae (15). Other genera included in this tribe are Ehrlichia and Neorickettsia. Our data indicate that $C$. ruminantium is a member of the order Rickettsiales rather than the Chlamydiales, as has been previously suggested (19), but it is monophyletic with a species of the type genus of the family Anaplasmataceae rather than the Ehrlichieae (15).

The phylogenetic relationship of $C$. ruminantium to other members of the order Rickettsiales has not previously been determined by analysis of nucleic acid sequences, since it has not been possible to cultivate and obtain large numbers of organisms in the past. We have circumvented this difficulty by preparing DNA from $C$. ruminantium cells grown in culture with bovine endothelial cells from which we have specifically amplified, cloned, and sequenced the $C$. ruminantium 16S rRNA coding region by using the polymerase chain reaction (PCR) $(9,22,25)$.

\section{MATERIALS AND METHODS}

Preparation of genomic DNA and amplified 16S rRNA gene. Genomic DNA was prepared (17) from the Crystal Springs isolate cultured in bovine endothelial cells derived from the aorta (28). C. ruminantium elementary bodies were collected from culture supernatants for extraction of DNA by centrifugation for $10 \mathrm{~min}$ at $2,000 \times g$ to remove the remnants of bovine cells lysed by the infection followed by centrifugation at $4^{\circ} \mathrm{C}$ for $30 \mathrm{~min}$ at $30,000 \times g$ to pellet the elementary bodies. DNA prepared from $C$. ruminantium purified in this fashion contains some bovine DNA, but $90 \mathrm{ng}$ of DNA from

\footnotetext{
* Corresponding author.

$\dagger$ This paper is University of Florida Agricultural Experiment Stations Journal Series no. R-02162.
}

this preparation was sufficient to amplify the $16 \mathrm{~S}$ rRNA gene(s) in vitro via PCR (9) by using a primer set described by Wilson et al. (25). PCR was performed in a volume of 100 $\mu l$ containing $10 \mathrm{mM}$ Tris- $\mathrm{HCl}(\mathrm{pH} 8.3), 50 \mathrm{mM} \mathrm{KCl}, 1.5 \mathrm{mM}$ $\mathrm{MgCl}_{2}, 0.2 \mathrm{mM}$ deoxynucleoside triphosphates, $1 \mu \mathrm{M}$ primer PC5, $1 \mu \mathrm{M}$ primer $\mathrm{PO}_{\mathrm{MOD}}$, and $2.5 \mathrm{U}$ of Taq polymerase. Thermal cycling was performed in a Coy Model 60 cycler in which the target DNA was denatured by incubation at $92^{\circ} \mathrm{C}$ for 10 min followed by 35 cycles of denaturation $\left(92^{\circ} \mathrm{C}\right.$ for 1 $\mathrm{min})$, primer annealing $\left(55^{\circ} \mathrm{C}\right.$ for $\left.3 \mathrm{~min}\right)$, and primer extension $\left(72^{\circ} \mathrm{C}\right.$ for $\left.3 \mathrm{~min}\right)$. At the end of cycling, the reaction mixture was held at $72^{\circ} \mathrm{C}$ for $10 \mathrm{~min}$ and cooled to $4^{\circ} \mathrm{C}$. A fragment of $1,463 \mathrm{bp}$, which ran as a single ethidium bromide-staining band on a $0.8 \%$ agarose gel, was amplified. The extreme $5^{\prime}$ and $3^{\prime}$ ends of the 16S rRNA gene and adjacent regions were amplified by inverse PCR (10) after the genomic DNA was cut with $X b a I$ and then ligated. The PCR primers at positions 64 to 50 and 1337 to 1351 (sequences shown in Table 1) were used under the conditions described above, and amplification produced a $1.8 \mathrm{-kb}$ fragment.

DNA sequence analysis and cloning. The 1,463-bp amplified DNA fragment was sequenced directly in both strands by the dideoxy chain termination method (18) by using ${ }^{32} \mathrm{P}$-endlabeled oligonucleotide sequencing primers labeled with T4 polynucleotide kinase (17). Suitable primers for sequencing the 16S rRNAs from members of the Rickettsiaceae were identified by aligning the sequences of $16 \mathrm{~S}$ rRNAs of members of the Rickettsiaceae available in the GenBank data base with that of Escherichia coli (from the gamma group of the Proteobacteria) by using the multiple-sequence alignment program, CLUSTAL (Intelligenetics, Mountain View, Calif.). Regions of the 16S rRNA sequence which were sufficiently conserved between members of the Rickettsiaceae and $E$. coli were identified at positions 50 to 64,297 to 311,558 to 572,787 to 806,942 to 956,1083 to 1097 , and 1337 to 1351 ( $E$. coli numbering). The corresponding and complementary oligonucleotide primers in Table 1 were prepared synthetically (14). In some cases, these primers were mixtures at one or two positions. The amplified DNA was also ligated into the SmaI site of pBluescript SK+ (Stratagene) after being prepared for cloning by polishing the ends with the Klenow fragment of DNA polymerase I (17). Regions of the sequence which were not determined with certainty by 
TABLE 1. PCR and sequencing primers

\begin{tabular}{|c|c|}
\hline $\begin{array}{l}\text { Primer } \\
\text { sequence }\end{array}$ & $\begin{array}{c}\text { Position in } E \text {. coli } \\
\text { 16S rRNA }\end{array}$ \\
\hline \multicolumn{2}{|l|}{ Forward } \\
\hline 5'AGAGTTTGATCCTGG3'a & $8-22$ \\
\hline 5'AACACATGCAAGTCG3'.. & $50-64$ \\
\hline 5'GAGAGGA(C/T)GATCAGC3' . & $297-311$ \\
\hline 5'GAAT (C/T)ACTGGGCGTA3' ... & $558-572$ \\
\hline 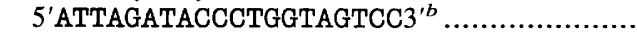 & $787-806$ \\
\hline 5'GTGGAG(C/T)ATG (C/T)GGTT3'. & $942-956$ \\
\hline 5'TGTTGGGTTAAGTCC3' ................ & $1083-1097$ \\
\hline 5'GGAATCGCTAGTAAT3' ... & $1337-1351$ \\
\hline \multicolumn{2}{|l|}{ Reverse } \\
\hline 5'TACCTTGTTACGACTT3' ${ }^{\prime}$. & $1507-1492$ \\
\hline 5'ATTACTAGCGATTCC3'. & $1351-1337$ \\
\hline 5'GGACTTAACCCAACA3' ... & $1097-1083$ \\
\hline $5^{\prime} \mathrm{AACC}(\mathrm{A} / \mathrm{G}) \mathrm{CAT}(\mathrm{A} / \mathrm{G}) \mathrm{CTCCAC} 3^{\prime}$ & $956-942$ \\
\hline 5'GGACTA(C/T/A)AGGGTATCTAAT3' .... & $806-787$ \\
\hline 5'TACGCCCAGT (A $/$ G)ATTC3' .. & $572-558$ \\
\hline 5'GCTGATC (A/G)TCCTCTC3' .. & $311-297$ \\
\hline 5'CGACTTGCATGTGTT3' .... & $64-50$ \\
\hline
\end{tabular}

a $\mathrm{PO}_{\mathrm{MOD}}$.
b $\mathrm{P}_{\mathrm{MOD}}$.

c PC5 (25).

direct sequencing of the PCR product were confirmed by sequencing the cloned fragment. The $1.8-\mathrm{kb}$ amplified fragment was cloned as a blunt fragment in the EcoRV cloning site of pBluescript $\mathrm{SK}+$, and the ends were sequenced by using T3 and T7 sequencing primers.

Phylogenetic analyses. Comparison of the $C$. ruminantium sequence with the published sequences of Anaplasma marginale (M60313), Coxiella burnetii (M21291), Chlamydia psittaci (M13769), Ehrlichia risticii (M21290), E. coli (J01695), Rochalimaea quintana (M11927), Rickettsia prowazekii (M21789), Rickettsia rickettsii (M21293), and Wolbachia persica (M21292), by using Planctomyces staleyi (M34126) as the outgroup, was performed both by parsimony analysis with PAUP (20) and by distance analysis to calculate the Kimura two-parameter distance (6) by using the DNADIST program (4). Then, the neighbor-joining method (16) and tree construction were performed by using the NEIGHBOR and DRAWGRAM programs, respectively, in the PHYLIP program package (4). Transversions were weighted $2: 1$ versus transitions in parsimony analysis. All sequences were aligned by using the CLUSTAL multiplesequence alignment program (available in the PC/Gene programs package available from IntelliGenetics) and examined by eye for regions with questionable homology.

Nucleotide sequence accession number. The nucleotide sequence described in this paper has been submitted to the EMBL data bank and assigned accession no. X61659.

\section{RESULTS AND DISCUSSION}

The sequence of the $C$. ruminantium 16S rRNA sequence is shown in Fig. 1. To compare $C$. ruminantium to $A$. marginale, the $16 \mathrm{~S}$ sequence of $A$. marginale was also amplified and sequenced as described above. During analysis of our data, the sequence of the 16S rRNA of $A$. marginale (M60313) was published (22). The sequence as reported (22) was identical to the sequence obtained in our laboratory for the Florida isolate (7) for the region comparable to bases 23 through 1491 ( $E$. coli $16 S$ rRNA numbering).

Regions comparable to bases 1 to 22,69 to 102,182 to 210 , 454 to 478,834 to 856,998 to 1044,1243 to 1294 , and 1449 to 1542 of the $E$. coli sequence for all taxa were excluded from parsimony analysis. For these regions, it was not possible to confidently determine whether the bases aligned in these regions represented homologous nucleotide positions. The sequences of the regions at the ends of the gene (bases 1 to 22 and 1492 to 1542 ) were excluded, since the $C$. ruminantium gene sequence was available from only a single strand in these regions. The 25 bases ( 454 to 478 ) were present in $C$. burnetii, $W$. persica, $E$. coli, $C$. psittaci, and $P$. staleyi but were absent from the other taxa. A total of 1,221 character

1 AAACTTGAGA GTTTGATCCT GGCTCAGAAC GAACGCTGGC GGCAAGCTTA ACACATGCAA 61 GTCGAACGGA CAGTTATTTA TAGCTTCGGC TATGAGTATC TGTTAGTGGC AGACGGGTGA 121 GTAATGCGTA GGAATCTGCC TAGTAGTATG 181 GTATAATCCC TGCGGGGGAA AGATTTATCG 241 GTTGGTAAGG TAATGGCTTA CCAAGGCAAT 301 CCACACTGGA ACTGAGATAC GGTCCAGACT 361 ACAATGGGCG AAAGCCTGAT CCAGCTATGC 421 AAACTCTTTT AATAGGGAAG ATAATGACGG 481 TGCCAGCAGC CGCGGTAATA CGGAGGGGGC 541 GGCACGTAGG TGGACTAGTA AGTTAAAAGT 601 TTTAATACTG CTAGACTAGA GGTCGAGAGA 661 ATTCGTAGAT ATTAGGAGGA ACACCGGTGG 721 CTGAGGTGCG AAAGCGTGGG GAGCAAACAG GAATAGCTAT TAGAAATGAT AGGTAATACT CTATTAGATG AGCCTACGTT AGATTAGCTA GATCTATAGC TGGTCTGAGA GGACGATCAG CCTACGGGAG GCAGCAGTGG GGAATATTGG CGCGTGAGTG AAGAAGGCCT TCGGGTTGTA TACCTATAGA AAAAGTCCCG GCAAACTCCG AAGCGTTGTT CGGAATTATT GGGCGTAAAG GAAATACCAA AGCTCAACTT TGGAGCTGCT GGATAGCGGA ATTCCTAGTG TAGAGGTGAA 781 ACGATGAGTG CTAAATGTGA GGATTTTATC TTTGTATTGT AGCTAACGCG TTAAGCACTC 841 CGCCTGGGGA CTACGGTCGC AAGACTAAAA CTCAAAGGAA TTGACGGGGA CCCGCACAAG 901 CGGTGGAGCA TGTGGTTTAA TTCGATGCAA CGCGAAAAAC CTTACCACTT TTTGACATGA 961 AGGTCGTATC CCTTTTAACC GAGGGAGTCA GTTCGGCTGG ACCTTACACA GGTGCTGCAT 1021 GGCTGTCGTC AGCTCGTGTC GTGAGATGTT GGGTTAAGTC CCGCAACGAG CGCAACCCTC 1081 ATCCTTAGTT ACCAACAGGT AATGCTGGGC ACTCTAAGGA AACTGCCAGT GATAAACTGG 1140 1141 AGGAAGGTGG GGATGATGTC AAGTCAGCAC GGCCCTTATA GGGTGGGCTA CACACGTGCT 1200 1201 ACAATGGCAA CTACAATAGG TTGCGAGACC GCGAGGTTTA GCTAATCCAA AAAAGTTGTC 1260 1261 TCAGTTCGGA TTGTTCTCTG CAACTCGAGA GCATGAAGTC GGAATCGCTA GTAATCGTGG 1320 1321 ATCATCATGC CACGGTGAAT ACGTTCTCGG GTCTTGTACA CACTGCCCGT CACGCCATGG 1380 1381 GAATTGGCTT AACTCGAAGC TGGTGTGCTA ACCGTAAGGA AGCAGCCATT TAAGGTTGGG 1440 1441 TTAGTGACTA GGGTGAAGTC GTAACAAGGT AGCTGTAGGT GAACCTGCGG CTGGATTACC 1500 1501 TCCTTT

FIG. 1. Sequence of the structural gene encoding the C. ruminantium 16S rRNA (413 A's, 298 C's, 434 G's, and 361 T's). 
A.

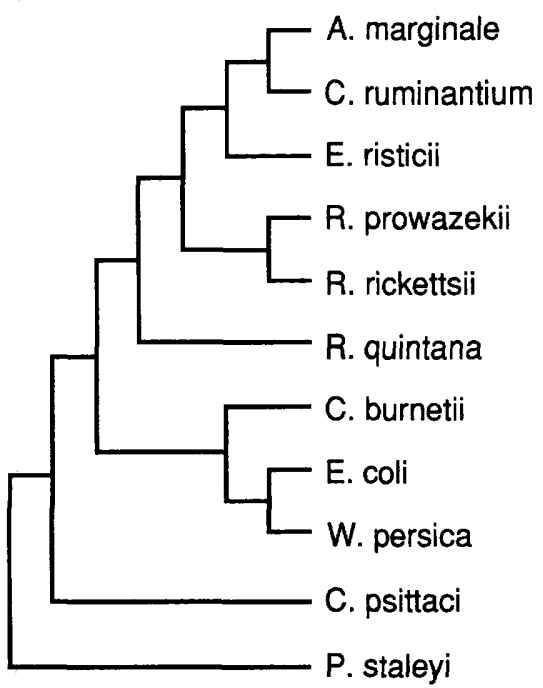

B.

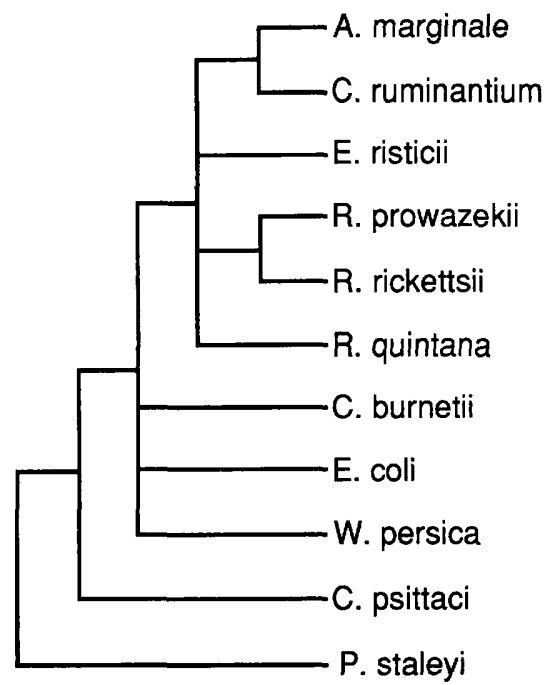

FIG. 2. (A) Most parsimonious tree relating C. ruminantium to 10 other bacterial taxa; (B) $95 \%$ consensus tree from parsimony analysis of 100 bootstrap replications from an 11-taxon data set used for panel $A$.

positions were examined, and 318 were phylogenetically informative by parsimony analysis.

The most parsimonious tree was determined for the 11taxon data set by using the branch and bound algorithm and by weighting transversions $2: 1$ versus transitions. This tree with a length of 1,619 steps and a consistency index of 0.493 is shown in Fig. 2A. Forty-four trees were within 31 additional steps of the most parsimonious tree. In all 44 trees, $C$. ruminantium was grouped with $A$. marginale and $C$. psittaci branching was placed at the deepest position on the tree at a large phylogenetic distance from $C$. ruminantium and the members of the Rickettsiales. Differences in the positioning of the other Proteobacteria relative to each other occurred among these longer trees. For example, the next most parsimonious tree, which was three steps longer, differed only by placement of the nodes separating $E$. coli, $W$. persica, and $C$. burnetii. The exact phylogenetic relationships of $E$. risticii and $R$. quintana to the other species in the alpha group of Proteobacteria and E. coli, C. burnetii, and $W$. persica among the gamma group of Proteobacteria are less certain (see below). The robustness of the essential features of the most parsimonious tree was examined by data resampling (bootstrap) analysis of 100 repetitions (20). This method defined the 95\% consensus tree shown in Fig. 2B. The clustering of $C$. ruminantium with $A$. marginale and of $R$. rickettsii with $R$. prowazekii, together with the deep branching of $C$. psittaci, was a fully supported feature of the tree. Thus, by parsimony analysis, $C$. ruminantium and $A$. marginale are monophyletic within the alpha group of Proteobacteria $(R$. rickettsii, $R$. prowazekii, $R$. quintana, $E$. risticii, $A$. marginale, and $C$. ruminantium), and this group forms a clade separate from the other three major bacterial groups, the gamma group of Proteobacteria (E. coli, C. burnetii, and $W$. persica), the Chlamydiales (C. psittaci), and the outgroup $(P$. staleyi), represented in the analysis.

The sequences, when examined by distance methods, imply the same groupings as those obtained by parsimony analysis. In the group of 11 taxa examined, 1,221 base positions were aligned as above, and a distance matrix was prepared by using the Kimura two-parameter (6) model of nucleotide substitution (Table 2) with the DNADIST program (4). When the sequences were plotted with $P$. staleyi as the outgroup via the neighbor-joining method (NEIGHBOR in PHYLIP [4]) (Fig. 3), C. ruminantium was clustered with $A$. marginale among the alpha group of Proteobacteria $(R$.

TABLE 2. Evolutionary distances adjusted by using Kimura two-parameter correction

\begin{tabular}{|c|c|c|c|c|c|c|c|c|c|c|c|}
\hline \multirow[b]{2}{*}{ Organism } & \multicolumn{11}{|c|}{ Evolutionary distance } \\
\hline & A. marginale & C. burnetii & C. psittaci & $\begin{array}{c}C . \\
\text { ruminantium }\end{array}$ & E. coli & E. risticii & P. staleyi & R. prowazekii & R. rickettsii & $\begin{array}{c}R . \\
\text { quintana }\end{array}$ & W. persica \\
\hline A. marginale & 0.0000 & & & & & & & & & & \\
\hline C. burnetii & 0.1760 & 0.0000 & & & & & & & & & \\
\hline C. psittaci & 0.2737 & 0.2553 & 0.0000 & & & & & & & & \\
\hline C. ruminantium & 0.0517 & 0.1875 & 0.2896 & 0.0000 & & & & & & & \\
\hline E. coli & 0.1910 & 0.1349 & 0.2567 & 0.2060 & 0.0000 & & & & & & \\
\hline E. risticii & 0.1323 & 0.1840 & 0.3080 & 0.1450 & 0.2150 & 0.0000 & & & & & \\
\hline$P$. staleyi & 0.2786 & 0.2520 & 0.2998 & 0.2868 & 0.2882 & 0.2987 & 0.0000 & & & & \\
\hline R. prowazekii & 0.1363 & 0.1737 & 0.2813 & 0.1373 & 0.2082 & 0.1488 & 0.2930 & 0.0000 & & & \\
\hline R. rickettsii & 0.1342 & 0.1696 & 0.2838 & 0.1352 & 0.2098 & 0.1500 & 0.2963 & 0.0041 & 0.0000 & & \\
\hline R. quintana & 0.1433 & 0.1612 & 0.2706 & 0.1535 & 0.1860 & 0.1745 & 0.2799 & 0.1384 & 0.1373 & 0.0000 & \\
\hline W. persica & 0.1914 & 0.1409 & 0.2597 & 0.1904 & 0.1524 & 0.2140 & 0.2724 & 0.1957 & 0.1959 & 0.1705 & 0.0000 \\
\hline
\end{tabular}




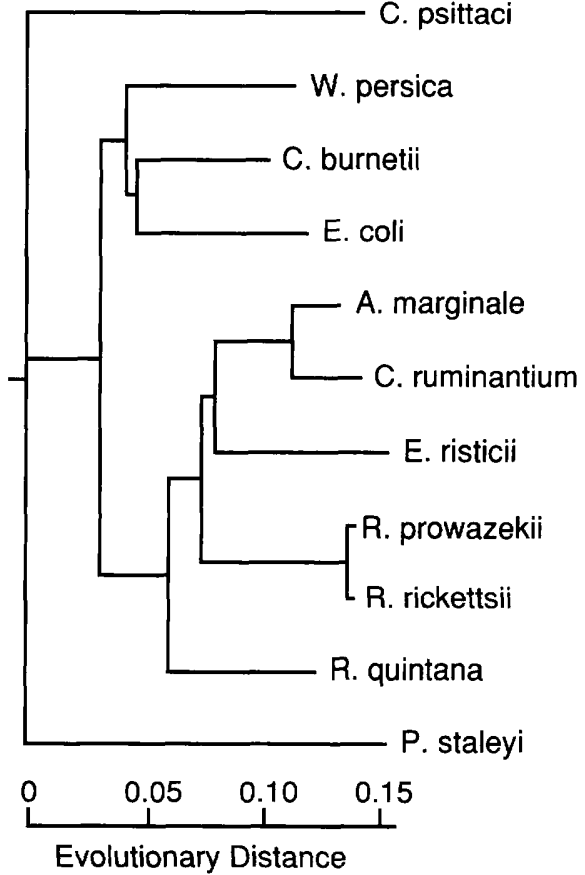

FIG. 3. Phylogenetic tree constructed from the evolutionary distances shown in Table 2 (adjusted by using the Kimura twoparameter correction). The tree is drawn to scale in arbitrary units of evolutionary distance for the taxa listed.

rickettsii, $R$. prowazekii, $R$. quintana, and E. risticii) (23), distinct from the gamma group of Proteobacteria (E. coli, $C$. burnetii, and $W$. persica) (23) and both $C$. psittaci and $P$. staleyi. The distance between $C$. ruminantium and $A$. marginale (0.0517) appears to be $\sim 12$ times that between the two species in the same genus, $R$. rickettsii and $R$. prowazekii (0.0041). C. psittaci was at a distance of $>0.25$ from all taxa examined. The only difference in conclusions between the parsimony and distance analyses was relative to the branching of $E$. coli, C. burnetii, and W. persica. The conclusions relative to these relationships were determined to be less reliable by the bootstrap analysis and, further, are unrelated to the present study.

A signature of nine base substitutions delineated the linkage of $A$. marginale with $C$. ruminantium and differentiated these two species from the 45 others in the alpha group of Proteobacteria examined in the RNA Database Project (12) (Table 3). Five of these substitutions (at positions 611, $988,1205,1427$, and 1510) differed from those for all 105 of the other Proteobacteria (alpha, beta, and gamma groups) examined. A sixth base of the signature, a transversion $(\mathrm{U} \rightarrow \mathrm{A})$ at position 508 , was seen for only two (Ectothiorhodospira halochloris A and E. halophila SL1) of the 105 other Proteobacteria examined (12). A previously defined sequence signature linking the Ehrlichia and Rickettsia subgroup (23) was examined in light of the new data. Of the 15 signature sequences, 6 were shared by the Cowdria and Anaplasma spp. and by Ehrlichia and Rickettsia spp., whereas in all positions, except position 1533, the sequences of $C$. ruminantium and $A$. marginale were identical. (At this position, $C$. ruminantium has a $\mathrm{T}$, and $A$. marginale has a $\mathrm{C}$.) This finding further supports the linkage between $C$. ruminantium and the Anaplasmataceae and supports removal of C. ruminantium from the Ehrlichieae.
TABLE 3. Sequence signature linking $C$. ruminantium and A. marginale

\begin{tabular}{lclll}
\hline Position $^{a}$ & $\begin{array}{c}\text { Base common to } \\
\text { C. } \begin{array}{c}\text { numinantium } \\
\text { and } \\
\text { A. marginale }\end{array}\end{array}$ & \multicolumn{3}{c}{$\begin{array}{c}\text { Base at position indicated for other } \\
\text { Proteobacteria }\end{array}$} \\
\cline { 3 - 5 } & Alpha & Beta & Gamma \\
\hline 45 & A & G or U & U & A, G, or U \\
396 & A & A, C, or G & A or C & A, C, G, or U \\
508 & A & C, G, or U & C & C or U \\
611 & U & A, C, or G & C or G & C or G \\
988 & U & C & C & C or U \\
1192 & C & U & U & U \\
1205 & A & C, G, or U & C or U & C or U \\
1427 & U & C & C & C \\
1510 & &
\end{tabular}

${ }^{a}$ Position (E. coli numbering) at which $C$. numinantium and $A$. marginale have a common sequence which differs from those of all other members of the alpha group of Proteobacteria currently in the RNA Database Project (45 species). Sequence differences from the beta and gamma groups of Proteobacteria reflect examination of 24 and 36 species, respectively.

Parsimony and distance analyses confirm the current taxonomic placement of $C$. ruminantium among the Rickettsiales (15), rather than among the Chlamydiales as had been suggested previously $(8,19,21)$. Previously, phylogenetic placement of $C$. ruminantium was based on qualitative phenotypic characters such as transmission by tick vectors, development in intracytoplasmic vacuoles, and similar host cell-type preference, etc. Conflicting conclusions have been drawn from analysis of different sets of these characters (19), since such characters are not necessarily good phylogenetic characters because of the potential for convergent evolution. Sequence data of the 16S rRNA gene refute the suggestion that $C$. ruminantium may be related phylogenetically to the Chlamydiales and fully support the close phylogenetic relationship between $C$. ruminantium and the Rickettsiales. Further, our parsimony and distance analyses of the $16 \mathrm{~S}$ rRNA data confirm the conclusion of Weisburg et al. (24) that the Chlamydia form a eubacterial branch distinct from the Rickettsiales.

Our data strongly indicate a closer phylogenetic relationship of the genus Cowdria to the Anaplasmataceae rather than to the Ehrlichieae (family Rickettsiaceae) (15) within the rickettsial sublineage in the Proteobacteria $(11,23,26$, 27). The phylogenetic positions of other species sharing the property of intimate association with eukaryotic cells, namely, Brucella abortus, Bartonella bacilliformis, and cat scratch disease bacillus, were recently evaluated from $16 \mathrm{~S}$ rRNA sequence data $(2,3,11)$. These organisms grouped among the Proteobacteria but within the alpha-2 subgroup $(2,3,11)$, represented by $R$. quintana in our studies (Fig. 2 and 3), which is distinct from the rickettsial sublineage (26a). Proper placement of $C$. ruminantium among the Anaplasmataceae, or determining whether it should form a tribe of its own, will require measuring the relatedness of Anaplasma to other genera in the Anaplasmataceae, including Aegyptianella, Eperythrozoon, and Haemobartonella. Sequences of the 16S rRNAs from species representative of these genera are not currently available, however.

The obligate, exclusive parasitism of erythrocytes among the Anaplasmataceae is currently a primary character linking this family. $C$. ruminantium does not share this characteristic, since it does not infect erythrocytes. Rather, it infects vascular endothelial cells, macrophages, and neutrophils. A study of the molecular phylogeny of the genera 
presently placed in the Anaplasmataceae would address whether the adaptation to obligate parasitism of the erythrocytes and/or plasma of vertebrates is a primitive character or whether it is a convergent life-style which has arisen independently multiple times among this group of organisms. The more distant relationship of $B$. bacilliformis (alpha-2 subgroup) $(2,11)$ to the other members of the Anaplasmataceae (rickettsial sublineage) suggests that the latter is the case. On the other hand, $C$. ruminantium, like all species of Anaplasma, is parasitic in ruminants exclusively. This raises the possibility that $C$. ruminantium and the four Anaplasma species described have arisen as descendants of a common ancestral parasite of ruminants.

\section{ACKNOWLEDGMENTS}

We thank C. Yunker and A. F. Barbet for providing C. ruminantium from culture for the preparation of DNA and C. J. Nairn and M. Miyamoto for comments on the manuscript.

This research was supported by USAID Cooperative Agreement AFR-0435-A-00-9084-00 and USDA CBAG grant 91-34135-6178.

\section{REFERENCES}

1. Barre, N., G. Uilenberg, P. C. Morel, and E. Camus. 1987. Danger of introducing heartwater onto the American mainland: potential role of indigenous and exotic Amblyomma ticks. Onderstepoort J. Vet. Res. 54:405-417.

2. Brenner, D. J., S. P. O'Connor, D. G. Hollis, R. E. Weaver, and A. G. Steigerwalt. 1991. Molecular characterization and proposal of a neotype strain for Bartonella bacilliformis. J. Clin. Microbiol. 29:1299-1302.

3. Dorsch, M., E. Moreno, and E. Stackebrandt. 1989. Nucleotide sequence of the 16S rRNA from Brucella abortus. Nucleic Acids Res. 17:1765.

4. Felsenstein, J. 1989. Phylogeny inference package (version 3.2). Cladistics 5:164-166.

5. Jukes, T. H., and C. R. Cantor. 1969. Evolution of protein molecules, p. 21-132. In H. N. Munro (ed.), Mammalian protein metabolism. Academic Press, New York.

6. Kimura, M. 1980. A simple method for estimating evolutionary rate of base substitutions through comparative studies of nucleotide sequences. J. Mol. Evol. 16:111-120.

7. McGuire, T. C., G. H. Palmer, W. L. Goff, M. I. Johnson, and W. C. Davis. 1984. Common and isolate-restricted antigens of Anaplasma marginale detected with monoclonal antibodies. Infect. Immun. 45:697-700.

8. Mohan, R. M. 1968. Diseases and parasites of buffaloes. 1 . Viral, mycoplasmal, and rickettsial diseases. Vet. Bull. 38:567576.

9. Mullis, K. B., and F. A. Faloona. 1987. Specific synthesis of DNA in vitro via a polymerase catalyzed chain reaction. Methods Enzymol. 155:335-350.

10. Ochman, H., J. W. Ajioka, D. Garza, and D. L. Hartl. 1989. Inverse polymerase chain reaction, p. 105-112. In H. A. Erlich (ed.), PCR technology. Stockton Press, New York.

11. O'Connor, S. P., M. Dorsch, A. G. Steigerwalt, D. J. Brenner, and E. Stackebrandt. 1991. 16S rRNA sequences of Bartonella bacilliformis and cat scratch disease bacillus reveal phylogenetic relationships with the alpha-2 subgroup of the class Proteobacteria. J. Clin. Microbiol. 29:2144-2150.

12. Olsen, G. J., N. Larsen, and C. R. Woese. 1991. The Ribosomal RNA Database Project. Nucleic Acids Res. 19(Suppl.):20172021.

13. Provost, A., and J. D. Bezuidenhout. 1987. The historical background and global importance of heartwater. Onderstepoort J. Vet. Res. 54:165-169.

14. Reddy, G. R., D. Chakrabarti, C. A. Yowell, and J. B. Dame. 1991. Sequence microheterogeneity of the three small subunit ribosomal RNA genes of Babesia bigemina: expression in erythrocyte culture. Nucleic Acids Res. 19:3641-3645.

15. Ristic, M., and D. L. Huxsoll. 1984. Tribe II. Ehrlichieae Philip $1957,948^{\mathrm{AL}}$, p. 704-711. In N. R. Krieg and J. G. Holt (ed.), Bergey's manual of systematic bacteriology, vol. 1. Williams \& Wilkins, Baltimore.

16. Saitou, N., and M. Nei. 1987. The neighbor-joining method: a new method for reconstructing phylogenetic trees. Mol. Biol. Evol. 4:406-425.

17. Sambrook, J., E. F. Fritsch, and T. Maniatis. 1989. Molecular cloning: a laboratory manual. Cold Spring Harbor Laboratory, Cold Spring Harbor, N.Y.

18. Sanger, F., S. Nicklen, and A. R. Coulson. 1977. DNA sequencing with chain-terminating inhibitors. Proc. Natl. Acad. Sci. USA 74:5463-5467.

19. Scott, G. R. 1987. The taxonomic status of the causative agent of heartwater. Onderstepoort J. Vet. Res. 54:257-260.

20. Swofford, D. L. 1990. PAUP: phylogenetic analysis using parsimony, version 3.0. Computer program distributed by the Illinois Natural History Survey, Champaign, Ill.

21. Uilenberg, G. 1983. Heartwater (Cowdria ruminantium infection): current status. Adv. Vet. Sci. Comp. Med. 27:427-480.

22. Weisburg, W. G., S. M. Barns, D. A. Pelletier, and D. J. Lane. 1991. 16S ribosomal DNA amplification for phylogenetic study. J. Bacteriol. 173:697-703.

23. Weisburg, W. G., M. E. Dobson, J. E. Samuel, G. A. Dasch, L. P. Mallavia, O. Baca, L. Mandelco, J. E. Sechrest, E. Weiss, and C. R. Woese. 1989. Phylogenetic diversity of the rickettsiae. J. Bacteriol. 171:4202-4206.

24. Weisburg, W. G., T. P. Hatch, and C. R. Woese. 1986. Eubacterial origin of chlamydiae. J. Bacteriol. 167:570-574.

25. Wilson, K. H., R. B. Blitchington, and R. C. Greene. 1990. Amplification of bacterial 16S ribosomal DNA with polymerase chain reaction. J. Clin. Microbiol. 28:1942-1946.

26. Woese, C. R. 1987. Bacterial evolution. Microbiol. Rev. 51:221271

26a.Woese, C. R. Personal communication.

27. Woese, C. R., E. Stackebrandt, W. G. Weisburg, B. J. Paster, M. T. Madigan, V. J. Fowler, C. M. Hahn, P. Blanz, R. Gupta, K. H. Nealson, and G. E. Fox. 1984. The phylogeny of purple bacteria: the alpha subdivision. Syst. Appl. Microbiol. 5:315326.

28. Yunker, C. E., B. Byrom, and S. Semu. 1988. Cultivation of Cowdria ruminantium in bovine vascular endothelial cells. Kenyan Vet. 12:12-16. 